\title{
CAUSALIDADE ENTRE OS RETORNOS DE MERCADOS DE CAPITAIS EMERGENTES E DESENVOLVIDOS
}

\author{
CAUSALITY BETWEEN STOCK RETURN RATES: EMERGING \\ VERSUS DEVELOPED CAPITAL MARKETS
}

WAGNER MOURA LAMOUNIER

Professor Adjunto do Programa de Mestrado em Ciências Contábeis

da Universidade Federal de Minas Gerais

E-mail:wagner@face.ufmg.br

\section{ELSE MONTEIRO NOGUEIRA}

Economista do Banco Santander/Banespa e Pós-Graduanda - MBA em Derivativos pelo Instituto Educacional da Bolsa de Mercadorias e Futuros E-mail: elsemonteiro@yahoo.com.br

\section{RESUMO}

Utilizando-se de instrumentais estatísticos para a análise de séries temporais, procurou-se verificar as relações entre os retornos dos principais mercados de capitais emergentes e dos principais mercados desenvolvidos. A amostra foi divida em dois períodos: entre 1995-2002 e entre 2003-2005, tendo em vista os momentos distintos dos mercados quanto à vulnerabilidade externa. No primeiro momento, apesar das diversas crises econômicas, verificou-se que apenas o retorno do mercado emergente da Rússia sofreu grandes impactos ante os choques dos retornos dos outros mercados. Entre 2003-2005, no entanto, os retornos de outros mercados emergentes, como o do Brasil e o do México, responderam de forma significativa aos choques nos retornos dos demais mercados analisados.

Palavras-chave: Diversificação Internacional de Portfolios, Mercado de Capitais, Causalidade de Granger, Vetores Auto-Regressivos, Funções de Resposta a Impulsos.

\section{ABSTRACT}

Using statistical instruments for the analysis of time series, - this work aims to verify the relation of returns of stock investments between the main emerging and the developed capital markets. The sample was divided in two periods: 1995-2002 and 2003-2005, in view of their different external vulnerability moments. At the beginning, - in spite of - several economic crises, only Russia's stock market returns - suffered great impacts, compared with those at other markets'. Between 2003-2005, however, the returns of other emerging markets, as Brazil's and Mexico's, answered in a more significant form to the shocks in the returns of other markets.

Keywords: International diversification of portfolios; Stock markets; Granger causality; Vector Auto Regressive model; Impulse Response Function. 


\section{INTRODUÇÃO}

A intensificação da interação econômica entre os países, sobretudo na última década, vem proporcionando uma expansão das oportunidades de investimento. Tendo em vista as recentes quedas das restrições ao capital internacional - que, atualmente, movimenta-se com maior liberdade - e o crescente processo de intensificação das relações de trocas comerciais e de serviços entre os diversos países, os investidores começaram a perceber a possibilidade de expandir seus negócios para além de suas fronteiras domésticas, ampliando o seu horizonte até mesmo para os mercados emergentes.

Segundo Mobius (1996), o termo mercado emergente, em relação ao mercado acionário, foi introduzido por executivos da International Finance Corporation (IFC) do Banco Mundial, quando começaram a se preocupar com o conceito de fundos de países e com o desenvolvimento do mercado de capitais nas regiões menos desenvolvidas do planeta. Gill (1993) apud Sanvicente e Leite (1994) afirma que era necessário recordar o processo histórico pelo qual os mercados financeiros de ações atravessaram após a II Guerra Mundial.

Segundo esse diretor da IFC, os esforços políticos para o fortalecimento dos mercados de ações, durante as décadas de 60 e 70, não chegaram a ser eficazes. " $A$ criação específica de um mercado de ações ajuda a sinalizar que naquele país havia um elevado grau de sofisticação comercial". (GILL apud SANVICENTE; LEITE, 1994, p. 118). Os mercados financeiros não eram vistos como importantes instrumentos de desenvolvimento econômico pelas autoridades governamentais. Naquela época, os mercados eram tidos como grandes centros de especulação.

A partir do momento em que a compreensão do fortalecimento dos mercados de capitais emergentes foi se espalhando por outros países, novas oportunidades começaram a aparecer para a comunidade financeira internacional. Segundo Van Agtmael (1993) apud Sanvicente e Leite (1994), seis possibilidades poderiam ser consideradas com a inclusão de ações desses mercados, ditos emergentes, no portfolio de um determinado investidor. São elas:

a) redução do risco via diversificação internacional;

b) elevado crescimento econômico (e oportunidades de retornos mais altos);

c) expansão do horizonte de investimentos, visando identificar ações subavaliadas;

d) os mercados emergentes contam com produtos mais competitivos em determinados setores de atividade:

e) oferecem oportunidades ainda não exploradas por grande parte dos investidores internacionais;

f) tendem a apresentar menor concentração de investidores institucionais.

Os investidores, no entanto, ainda precisam de cautela ao decidir investir nos mercados emergentes. Estudá-los, compreendendo as suas dinâmicas, constitui um importante instrumento a fim de se alcançarem os objetivos propostos com a aplicação de recursos nesses mercados. Segundo Mobius (1996), os mercados emergentes exigem maior pesquisa e cuidados com a custódia do que normalmente é esperado nos mercados desenvolvidos e, com freqüência, implicam um maior grau de risco assumido por parte dos investidores.

\subsection{O Problema e sua Importância}

Em conseqüência da globalização financeira, múltiplas são as oportunidades de novos investimentos e de novos negócios. Segundo Pagan e Soydemir (2000), desde a década de 80, investir em mercados emergentes como estratégia de diversificação internacional tem se tornado comum tanto para os investidores de países desenvolvidos quanto em desenvolvimento. Dessa forma, Miller (2005) destaca que os investidores começam a intensificar o processo da diversificação internacional de seus portfolios, ou seja, aceleram o processo de alocar seus recursos além de suas fronteiras domésticas. A autora cita que o mercado norteamericano, principalmente após os recentes escândalos de grandes corporações como a Enron, parece dividir a preferência dos investidores com outros mercados. Segundo esse autor, trabalhadores norte-americanos, por exemplo, já aplicam parte de suas poupanças de aposentadoria em mercados emergentes e até mesmo os alemães, famosos pelo conservadorismo, já possuem cerca de $30 \%$ de seus portfolios fora da Alemanha.

O perfil dos investimentos, também, vem se alterando. O que antes era apenas uma troca de investimentos entre Europa e Estados Unidos (EUA) expande-se para outras nações do mundo. Miller (2005) afirma que os títulos dos países emergentes, em especial os da Rússia e outros europeus em desenvolvimento, atraem o interesse do capital internacional. Em 2004, por exemplo, foram comprados US $\$ 72.5$ bilhões de dólares de títulos dos países emergentes ante US\$5.4 bilhões em 2002.

Entender o funcionamento e as relações entre os mercados emergentes e capitalizados torna-se um instrumento necessário para que o investidor saiba como alocar de maneira mais eficiente os seus recursos de modo a minimizar suas perdas. Para examinar os benefícios da diversificação internacional, é necessário analisar a correlação entre os mercados, bem como os riscos e retornos de cada um. Os efeitos da diversificação internacional só poderão ser bem analisados se a comunidade financeira internacional compreender de que maneira e quais os mecanismos que influenciam o comportamento das Bolsas de Valores. Para Elton et al. (2004, p.233), "a conveniência de uma estratégia de diversificação internacional depende do coeficiente de correlação entre mercados, do risco de cada mercado e dos retornos em cada mercado".

\subsection{Objetivos}

Em termos gerais, essa pesquisa busca analisar a dinâmica da interação entre os principais mercados bursáteis 
emergentes mundiais em cada continente, quais sejam: mercados do Brasil, da Rússia, da Índia, da China e do México e dos principais mercados bursáteis capitalizados: dos EUA, do Japão e do Reino Unido. Buscar-se-á avaliar o grau de interdependência que os mercados emergentes possuem entre si e com os mercados de maior capitalização dentro do contexto financeiro internacional.

Especificamente, este trabalho pretende:

a) avaliar a sensibilidade dos mercados emergentes diante das oscilações (choques) nas Bolsas desenvolvidas, procurando identificar se são mais sensíveis aos impactos regionais (Bolsas do mesmo continente) ou mais sensíveis aos efeitos globais, não importando, dessa forma, a proximidade geográfica;

b) verificar se as relações de interdependência dos mercados se diferem, tendo em vista momentos econômicos distintos: períodos de estabilidade $x$ períodos de fortes crises internacionais;

c) mensurar por quanto tempo choques, em uma Bolsa desenvolvida, terão efeito nos mercados ditos mais vulneráveis;

d) mensurar por quanto tempo choques, em uma das Bolsas emergentes, terão efeito nos outros mercados.

\section{METODOLOGIA}

\subsection{Referencial Teórico}

O marco teórico deste trabalho refere-se à análise dos mercados bursáteis de países emergentes como Brasil, Rússia, Índia, China e México procurando mostrar como respondem a oscilações entre si e como se comportam ante o desempenho das Bolsas desenvolvidas dos EUA, Japão e Reino Unido.

$\mathrm{Na}$ literatura de finanças, muitos são os estudos que procuraram analisar o grau de independência entre os mercados financeiros de diversos países. Essas pesquisas são importantes para gerar informações para investidores e demais agentes interessados, sobre como os mercados interagem. Nesse sentido, Aggarwal e Rivoli (1989) procuraram examinar a relação entre o mercado norte-americano e quatro mercados emergentes asiáticos mostrando que há significativa dependência entre o comportamento desses mercados. O estudo desses autores evidenciou forte relação entre os mercados, sobretudo durante o "Crash" de 1987.

Pagan e Soydemir (2000) utilizaram o modelo de Vetores Auto-Regressivos (VAR) para analisar a extensão de interdependência entre os mercados latino-americanos. Eles consideraram os seguintes países latinos: Chile, Argentina, Brasil e México. Os resultados estimados pelas funções de resposta a impulsos evidenciaram uma forte relação entre 0 mercado mexicano e o norte-americano. Também se sugere uma relação mais fraca, mas significante, para os outros países em relação ao mercado de Wall Street. A diferença das transmissões pode estar vinculada às características específicas de cada país bem como aos seus fundamentos econômicos.

Um estudo no continente asiático procurou examinar a relação entre os mercados de oito países orientais (Hong Kong, Indonésia, Coréia, Malásia, Filipinas, Cingapura, Taiwan e Tailândia) com os mercados do Japão e dos Estados Unidos. Cheung e Mak (1992) chegaram à conclusão de que os mercados asiáticos analisados são mais sensíveis às oscilações do mercado norte-americano, mostrando que efeitos da estrutura global (representado por Wall Street) são mais determinantes no comportamento desses mer- cados do que a estrutura regional (representada pelo mercado japonês). Apenas Coréia, Taiwan e Tailândia não se mostraram muitos sensíveis, talvez pela forte restrição ao capital estrangeiro no mercado bursátil desses países.

Kanas (1998), utilizando as metodologias de Traços Estatísticos Multivariados e dos métodos de Cointegração propostos por Johansen (1988) e Bierens (1997) apud Kanas (1998), não encontrou evidências de que o mercado norte-americano esteve relacionado com as seis principais Bolsas de Valores da Europa (Reino Unido, Alemanha, França, Suíça, Itália e Holanda) durante o período de 19831996, sugerindo a potencialidade dos ganhos aos investidores via diversificação no longo prazo.

Contrariando os resultados encontrados por Kanas (1998), Gerrits e Yuce (1999) utilizaram dados diários entre março de 1990 e outubro de 1994 para analisar a interdependência entre os mercados da Alemanha, Reino Unido, Holanda e Estados Unidos. Os autores concluíram que o mercado norte-americano exerce um impacto significativo nas Bolsas desses três países europeus. Além disso, podese dizer que a interdependência entre os três mercados se dá tanto no curto quanto no longo prazo. A diversificação, de acordo com esse estudo, não seria capaz de reduzir, sensivelmente, o risco dos portfolios sem sacrificar as expectativas de retornos.

No Brasil, Tabak e Lima (2003) procuraram analisar a causalidade e a cointegração entre os mercados da Argentina, Brasil, Chile, Colômbia, México, Peru, Venezuela e Estados Unidos. Não foram encontradas evidências de cointegração entre mercados latino-americanos e entre esses com o mercado norte-americano. Mesmo assim, os autores não descartaram, através dos resultados apresentados pelo teste de Granger, uma possível causalidade de curto prazo. Além disso, afirmam que choques no mercado norte-americano são capazes de afetar o comportamento dos mercados latinos de maneira heterogênea. O mercado mexicano, por exemplo, sofre um impacto mais expressivo do que o dos outros países, provavelmente explicado pela maior integração entre as economias mexicana e norteamericana. 


\subsection{Modelo Econométrico}

\subsubsection{Testes de raiz unitária}

Segundo Tabak e Lima (2003), quando se testam relações entre mercados financeiros, não é apropriado utilizar a estatística t-student para conduzir inferências estatísticas, uma vez que as variáveis da regressão poderão apresentar tendência, variâncias oscilantes ao longo do tempo e padrões sazonais fixos, ou seja, as séries podem não ser estacionárias.

A não-estacionariedade das séries temporais poderá ser verificada por meio de testes de raízes unitárias. Um dos testes mais importantes a fim de identificar a presença de raízes unitárias (série não-estacionária) é o teste de Dickey Fuller expandido (ADF). Esse teste permite verificar a estacionariedade das séries, identificando a presença de não-estacionariedade pela incidência de tendências estocásticas, determinísticas ou a junção de ambas.

O ADF consiste na estimação de uma regressão da primeira diferença da série que poderá incorporar termos de tendência (determinística) $(\tau)$. Além disso, o modelo permite que $\Delta y_{t}$ possa ser gerado por um modelo AR de ordem superior (inclusão dos termos $\Delta y_{t \cdot k}$ ). A equação (1) representa a equação de teste do modelo ADF:

$$
\Delta y_{t}=\mu+\alpha \tau+(\beta-1) y_{t-1}+\sum_{p=1}^{k-1} \phi_{p} \Delta y_{t-p}+\varepsilon_{t}
$$

em que: $\mu$ é o drift; $\tau$ é o termo de tendência linear; $k$ é o número de defasagens e $\varepsilon_{\mathrm{t}}$ é o erro aleatório do tipo white noise (ruído branco). O teste será dado pelas hipóteses:

$H_{0}=\mu=\alpha=(\beta-1)=0$ (Raiz Unitária) versus $H_{1}=$ alguns dos termos $(\mu, \alpha,(\beta-1)) \neq 0$.

Segundo Hamilton (1994), é importante verificar, antes de realizar o teste, se as séries "aparentam" possuir alguma tendência e média diferente de zero para a inclusão dos termos, como variáveis de intercepto e de tendência determinística, a fim de não reduzir o poder do teste.

Outro problema relacionado ao ADF, segundo Lamounier (2003), estaria relacionado à determinação da ordem $p$ de defasagens. Nessa pesquisa, será utilizada a minimização dos critérios de informação de AIC ou SBIC como critérios de escolha.

Existe um outro fator que poderia inviabilizar a utilização do ADF: a premissa de que o erro aleatório seja do tipo ruído branco. Caso $\varepsilon_{\mathrm{t}}$ quebre um dos seus pressupostos, o teste de Phillips-Perron (PP) será o mais adequado. Segundo Lamounier (2003), o teste PP constitui-se numa generalização do teste DF, que procura corrigir as estatísticas $t$ dos coeficientes estimados ao invés de acrescentar os termos das diferenças defasadas nas equações do teste. Desta forma, o modelo permite que os erros (resíduos) sejam dependentes e / ou heterocedásticos. A equação do teste é dada por:

$$
\Delta y_{t}=\mu+\rho y_{t-1}+\varepsilon_{t}
$$

cuja hipótese nula é dada por $H_{0}=\rho=1$, ou seja, a série $y_{t}$ segue um processo do tipo passeio aleatório.

\subsubsection{Teste de Causalidade de Granger}

Granger (1969) apud Griffiths; Hill; Judge (1993) afirma que uma variável $x_{1 t}$ é conhecida como "Granger caused" por $x_{2 t}$ se informações passadas e correntes de $x_{2 t}$ ajudam a melhorar as previsões de $x_{1}$, e/ou vice-versa. Segundo Gujarati (2000), o teste de causalidade de Granger é um instrumento eficiente, que tem como objetivo detectar a direção de causalidade quando houver temporariamente uma relação de liderança e defasagem entre duas variáveis. $\mathrm{O}$ autor, também, afirma que a direção de causalidade dependerá do número de termos defasados incluídos no modelo. Considerem-se as seguintes séries, $x_{1}$ e $x_{2}$, não cointegradas:

$$
\begin{aligned}
& x_{1 t}=\alpha_{0}+\sum_{i=1}^{k} \alpha_{1 i} x_{1 t-i}+\sum_{i=1}^{k} \alpha_{2 i} x_{2 t-i}+\varepsilon_{1 t} \\
& x_{2 t}=\beta_{0}+\sum_{i=1}^{k} \beta_{1 i} x_{1 t-i}+\sum_{i=1}^{k} \beta_{2 i} x_{2 t-i}+\varepsilon_{2 t}
\end{aligned}
$$

Se um ou mais coeficientes $\alpha_{2 i}$ forem estatisticamente diferentes de zero para as diferentes defasagens, então, pode-se rejeitar a ausência da causalidade. Assim, tem-se que $x_{2}$ causa $x_{1}$ no sentido de Granger. Se um ou mais coeficientes $\beta_{1 i}$ forem estatisticamente significativos, a direção da causalidade será de $x_{1}$ para $x_{2}$. Se ambos os parâmetros, $\alpha_{2 i}$ e $\beta_{1 i}$, forem diferentes de zero, então, pode-se afirmar que existe causalidade bidirecional, ou seja, $x_{2}$ causa $x_{1}$, assim como $x_{1}$ causa $x_{2}$. A aceitação/rejeição da hipótese nula estará fundamentada na interpretação da estatística $F$. Para Stock e Watson (2004, p.305):

Uma aplicação útil da estatística $\mathrm{F}$ na previsão de séries temporais é testar se as defasagens de um dos regressores incluídos possuem um conteúdo preditivo útil, muito superior ao dos outros regressores do modelo. A afirmação de que uma variável não possui conteúdo preditivo corresponde à hipótese nula de que os coeficientes de todas as defasagens daquela variável são iguais a zero.

\subsubsection{O modelo Vetorial Auto-Regressivo (VAR)}

Para Brooks (2002), o modelo VAR é um modelo de equações simultâneas cujas variáveis dependentes estão em função de diferentes combinações de suas próprias defasagens. Griffiths; Hill; Judge (1993) consideram a possibilidade de que um número $k$ de séries temporais, randômicas e conjuntamente determinadas, é capaz de desenvolver um modelo de previsão que captura os comportamentos dinâmicos e de interdependência entre essas séries. Assim, uma vez que será testada a interdependência entre os mercados financeiros, o modelo mais adequado a ser utilizado, neste estudo, é o modelo VAR.

Para esclarecer a metodologia do modelo VAR, pode-se utilizar a abordagem de Stock e Watson (2004) que procuraram exemplificar esse modelo da maneira mais simples possível. Considerem-se duas séries temporais, $y_{1}$ e $y_{2}$, ou seja, $k=2$. Assim, tem-se que: 
$y_{1 t}=\alpha_{10}+\alpha_{11} y_{1 t-1}+\ldots+\alpha_{l p} y_{1 t-p}+\beta_{11} y_{2 t-1}+\ldots+\beta_{l p} y_{2 t-p}+\varepsilon_{l t}$

$y_{2 t}=\alpha_{20}+\alpha_{21} y_{2 t-1}+\ldots+\alpha_{2 p} y_{2 t-p}+\beta_{21} y_{1 t-1}+\ldots+\beta_{2 p} y_{1 t-p}+\varepsilon_{2 t}$

em que: $y_{1 t}$ e $y_{2 t}$ são os valores correntes das variáveis endógenas; $\alpha_{i p}$ e $\beta_{i p}$ são os coeficientes e $\varepsilon_{i t}$ são os termos de erro do tipo ruído branco.

Analisando as equações (5) e (6), pode-se generalizar o modelo VAR de ordem $p$, de acordo com a forma matricial:

$$
y_{t}=\delta+\varphi_{1} y_{t-1}+\varphi_{2} y_{t-2}+\ldots+\varphi_{p} y_{t-p}+\varepsilon_{t}
$$

em que:

$$
y_{t}=\left[\begin{array}{c}
y_{1 t} \\
y_{2 t} \\
\ldots \\
y_{k t}
\end{array}\right] ; \delta=\left[\begin{array}{c}
\alpha_{10} \\
\alpha_{20} \\
\ldots \\
\alpha_{k 0}
\end{array}\right] ; \varphi_{i}=\left[\begin{array}{cccc}
\phi_{1,1, p} & \ldots & \ldots & \phi_{1, k, p} \\
\ldots & \ldots & \ldots & \ldots \\
\ldots & \ldots & \ldots & \ldots \\
\phi_{k, 1, p} & \ldots & \ldots & \phi_{k, k, p}
\end{array}\right] ; \varepsilon_{t}=\left[\begin{array}{c}
\varepsilon_{1 t} \\
\varepsilon_{2 t} \\
\ldots \\
\varepsilon_{k t}
\end{array}\right]
$$

Stock e Watson (2004) afirmam que o modelo VAR é um conjunto de equações para $k$ de séries temporais, cujos regressores são valores defasados das variáveis dependentes de todas as $k$ séries. Assim, conforme colocado por Griffiths; Hill; Judge (1993), o modelo VAR expressa os valores correntes das variáveis dependentes em função da variável de intercepto $\left(\alpha_{i 0}\right)$ e dos valores defasados das variáveis endógenas.

Ao se trabalhar com o modelo VAR, o pesquisador deve utilizar séries temporais $y_{t}$ estacionárias. As vantagens da utilização desse modelo são múltiplas. Brooks (2002) cita, por exemplo, o fato de que não é necessário especificar quais variáveis são endógenas e quais são exógenas uma vez que, nesse modelo, todas as variáveis são consideradas endógenas. Além disso, uma vez que todas as variáveis do modelo sejam conhecidas, é possível estimar, separadamente, cada equação utilizando o método dos Mínimos Quadrados Ordinários (MQO). Outra vantagem, colocada por Brooks (2002), é o fato de que esse modelo tem se mostrado capaz de gerar previsões melhores do que os modelos estruturais tradicionais.

\subsubsection{A função de resposta a impulsos}

Segundo Lamounier e Silva (1998), a interpretação direta dos coeficientes estimados em um modelo VAR, muitas vezes, não é o ponto fundamental da análise desse tipo de modelos.

O modelo VAR apresenta sua principal contribuição para a análise de relações empíricas pela possibilidade da derivação, a partir dos coeficientes estimados, da função de resposta aos impulsos e da decomposição da variância do sistema. (LAMOUNIER; SILVA, 1998, p. 951)

A fim de se analisar como um choque em um mercado poderá gerar efeitos em outros mercados, deve-se utilizar a função de resposta aos impulsos. Essa função indica a resposta de uma variável endógena do sistema ante a choques exógenos.

Um conceito importante e que terá utilidade para interpretação empírica será dado a partir da seguinte dedução. Segundo Tabak e Lima (2003), um modelo VAR pode ser rescrito como um vetor de médias móveis infinito - VMA $(\infty)$ :

$$
y_{t}=\mu+\varepsilon_{t}+\psi_{1} \varepsilon_{t-1}+\ldots+\psi_{n} \varepsilon_{t-n}+\ldots
$$

Assim, conforme Hamilton (1994), se o primeiro termo $\varepsilon_{t}$ é alterado pelo parâmetro $\delta_{1}$ ao mesmo tempo que o segundo é modificado por $\delta_{2}$ e o i-nésimo elemento por $\delta_{n}$, então a combinação dos efeitos dessas mudanças no valor do vetor $y_{t+s}$, será dada por:

$$
\Delta y_{t+s}=\frac{\partial y_{t+s}}{\partial \varepsilon_{i t}} \delta_{1}+\frac{\partial y_{t+s}}{\partial \varepsilon_{2 t}} \delta_{2}+\ldots+\frac{\partial y_{t+s}}{\partial \varepsilon_{n t}} \delta_{n}=\psi_{s} \delta
$$

Assim, derivando-se (24) em relação ao valor de y no período $t+s$, tem-se:

$$
\frac{\partial y_{t+s}}{\partial \varepsilon_{t}}=\psi_{s}
$$

em que $\psi_{s}$ são multiplicadores dinâmicos do sistema e representam a resposta do modelo, ou seja, de todas as séries $y_{1}, y_{2}, \ldots, y_{n}$ do vetor $y$, em relação a um choque unitário em cada uma das variáveis do modelo. O elemento da i-ésima linha e da j-ésima coluna de $\psi_{\text {s }}$ indica a conseqüência de uma variação de uma unidade na j-ésima variável no período $t\left(\varepsilon_{j t}\right)$ para o valor da i-ésima variável no tempo $t+s\left(\mathrm{y}_{\mathrm{t}+\mathrm{s}}\right)$, tudo o mais constante. Em resumo, um choque na i-ésima variável de um sistema VAR não terá impacto somente naquela variável, mas em todas as variáveis do sistema. Para Enders (1995), uma forma bastante útil de caracterizar a função de resposta a impulso é através da análise do seu gráfico que permite examinar o efeito de um choque $\varepsilon_{j t}$ em cada variável do sistema.

\subsection{Dados, Procedimentos e Softwares utilizados}

Os dados utilizados neste trabalho compreendem os principais índices de mercado diários de fechamento das Bolsas de Valores estudadas. Segundo Leite e Sanvicente (1994), os índices funcionam como termômetro do mercado acerca das expectativas dos investidores diante do desempenho da economia de um país. Além disso, são eles as "verdadeiras réguas para a avaliação quantificada das alterações subjetivas do ânimo dos investidores, e a intensidade de suas flutuações funciona como parâmetro indispensável para a análise do risco". Os dados foram coletados do banco de dados dos sites do Yahoo Finance, Bloomberg e RTS Stock Exchange. Utilizaram-se os índices estabelecidos na Tabela 10.

A amostra será dividida em dois períodos. No primeiro momento, que se estende de setembro de 1995 a dezembro de 2002, o estudo terá como objetivo verificar como é o comportamento e a interação dos mercados bursáteis ante 
Tabela 1 || Índices e Mercados Analisados

\begin{tabular}{c|c|c|c} 
PAÍS & BOLSA & ÍNDICE & SIGLA \\
BRASIL & SÃO PAULO & IBOVESPA & IBV \\
\hline RÚSSIA & MOSCOU & RTS & RTS \\
\hline ÍNDIA & NOVA DÉLI & S\&P 500 CNX NIFTY & CNX \\
\hline CHINA & SHANGAI & SHANGAI COMPOSITE INDEX & SCI \\
\hline MÉXICO & CIDADE DO MÉXICO & Índice Precios \& Cotizaciones & IPC \\
\hline ESTADOS UNIDOS & NOVA YORK & NIIKKEI 225 & SP \\
\hline JAPÃO & TÓQUIO & FTSE 100 & NIK \\
\hline REINO UNIDO & LONDRES & FTSE
\end{tabular}

Fonte: Resultado da pesquisa

as diversas crises que afetaram as nações em análise, tais como a crise mexicana, russa, brasileira e argentina. No segundo momento, a mesma análise será feita para o período de janeiro de 2003 a agosto de 2005. Esse intervalo caracteriza-se por um período de relativa estabilidade nos mercados financeiros internacionais, em que não se verificou nenhum momento de forte instabilidade ou crise de confiança na estrutura geo-econômica mundial. Assim, procura-se verificar se os mercados apresentam, de certa forma, uma interação semelhante à observada no período anterior.

Será importante ao longo deste trabalho, ressaltar alguns fatores que serão levados em consideração a fim de que os resultados possam ser analisados de forma mais transparente. Assume-se, nesta pesquisa, que, uma vez racionais, os investidores, ao decidirem sobre a alocação de seus recursos em países fora do seu contexto doméstico, estarão realizando hedge cambial a fim de protegerem o seu patrimônio quanto a futuras oscilações no mercado de divisas. Assim, o risco cambial será nulo e o risco em aná- lise será apenas aquele intrínseco à economia escolhida, ou seja, o risco doméstico, definido por Elton et al. (2004), como aquele relevante para mensurar o risco e que estarão expressos em sua unidade corrente local.

Nas datas em que as Bolsas estiveram fechadas, devido a feriados nacionais ou por quaisquer outros motivos, os índices utilizados, para o dia em questão, foram aqueles referentes ao último dia de negociação antes da paralisação. Outra informação importante é a correção do Índice lbovespa da Bolsa de Valores do Brasil. Em março de 1997, a Bolsa realizou em seu índice um split, dividindo a sua base por dez, sem alterar a metodologia da sua composição. Sendo assim, houve uma correção dos índices posteriores a onze de março de 1997. Uma vez que os retornos serão calculados pela sua forma logarítmica, a simples multiplicação por dez dos retornos posteriores não afeta o cálculo do retorno do índice. A estimação dos modelos e testes foi implementada com o software E-views, versão 4.1.

\section{RESULTADOS E DISCUSSÃO}

O primeiro passo para a estimação do modelo configurou-se na execução dos testes de raízes unitárias de Phillips-Perron (PP) e de Dickey Fuller expandido (ADF) para as séries dos retornos dos índices de todas as Bolsas estudadas. Conforme Tabela $2 \boldsymbol{\theta}$, pode-se perceber que as séries dos retornos são estacionárias, ou seja, não apresentam raízes unitárias uma vez que, para ambos os testes, $\tau_{\text {calculado }} \geq \tau_{\text {critico }}$ para os dois períodos cujas séries serão analisadas. O nível de significância considerado foi de $10 \%$.

Dessa forma, o teste de causalidade de Granger foi estimado para ambos os períodos a fim de se determinar o grau de endogeneidade entre as séries dos retornos visando à estimação do modelo VAR, além de verificar quais retornos estariam melhorando a previsibilidade de outros. Foram realizados testes para duas, quatro, seis e oito defasagens a fim de se verificar se o número de lags interfere nos resultados apresentados.

O teste de causalidade de Granger é bastante sensível ao número de defasagens utilizadas na análise.
[...] Do ponto de vista prático, se o teste de causalidade de Granger não for muito sensível ao tamanho da defasagem, teremos mais confiança em nossas conclusões do que se os resultados forem muito sensíveis ao tamanho da defasagem. (GUJARATI, 2000, p.629)

Para critério de rejeição / não rejeição da hipótese nula do teste de causalidade de Granger, foi considerado um valor crítico de $10 \%$. Dessa forma, dado um valor-p menor do que o valor crítico deve-se rejeitar a hipótese nula. Caso contrário, não se rejeita a hipótese nula. Os resultados apresentados no Tabela $3 \bullet$ indicam a relação de causalidade entre os mercados capitalizados para o período de 1995 a 2002. Os resultados sugerem que a direção de causalidade ocorre somente do retorno do mercado londrino para o retorno do mercado norte-americano em todos os lags apresentados.

Além disso, existe uma relação de direção de causalidade entre todos os retornos apresentados, em relação ao retorno do mercado japonês, com exceção dos mercados 
Tabela 2 Teste de Raiz Unitária

\begin{tabular}{l|c|c|c|c} 
& \multicolumn{2}{c|}{ Teste PP } & \multicolumn{2}{c}{ Teste ADF } \\
\hline \multicolumn{1}{c|}{ RETORNO } & $\mathbf{1 9 9 5 - 2 0 0 2}$ & $\mathbf{2 0 0 3 - 2 0 0 5}$ & $\mathbf{1 9 9 5 - 2 0 0 2}$ & $\mathbf{2 0 0 3 - 2 0 0 5}$ \\
\hline IBV & $-41,924$ & $-24,808$ & $-41,959$ & $-24,829$ \\
\hline RTS & $-37,643$ & $-23,726$ & $-37,484$ & $-23,686$ \\
\hline CNX & $-41,329$ & $-23,514$ & $-41,320$ & $-19,570$ \\
\hline SCI & $-44,356$ & $-25,856$ & $-44,356$ & $-25,823$ \\
\hline IPC & $-39,970$ & $-23,731$ & $-40,058$ & $-23,818$ \\
\hline SP & $-44,473$ & $-28,939$ & $-43,934$ & $-28,923$ \\
\hline NIK & $-46,913$ & $-25,872$ & $-46,617$ & $-25,871$ \\
\hline FTSE & $-43,269$ & $-29,367$ & $-29,045$ & $-29,207$ \\
\hline Valor Crítico 10\% & $-\mathbf{3 , 1 2 8}$ & $\mathbf{- 3 , 1 3 1}$ & $\mathbf{- 3 , 1 2 8}$ & $\mathbf{- 3 , 1 3 1}$
\end{tabular}

Fonte: Resultados da pesquisa

Tabela 3 - Teste de Causalidade de Granger: mercados capitalizados (1995-2002)

\begin{tabular}{|c|c|c|c|c|c|c|c|c|}
\hline \multirow[b]{2}{*}{ Hipótese Nula (Ho) } & \multicolumn{2}{|c|}{$\operatorname{Lag}(2)$} & \multicolumn{2}{|c|}{$\operatorname{Lag}(4)$} & \multicolumn{2}{|c|}{$\operatorname{Lag}(6)$} & \multicolumn{2}{|c|}{$\operatorname{Lag}(8)$} \\
\hline & Prob. & F Statistic & Prob. & F Statistic & Prob. & F Statistic & Prob. & F Statistic \\
\hline \multicolumn{9}{|l|}{ SP não é causado por: } \\
\hline NIK & 0,167 & 1,790 & 0,445 & 0,930 & 0,429 & 0,991 & 0,196 & 1,388 \\
\hline FTSE & 0,093 & 2,380 & 0,065 & 2,215 & 0,063 & 1,993 & 0,001 & 3,410 \\
\hline IBV & 0,585 & 0,536 & 0,835 & 0,363 & 0,962 & 0,244 & 0,970 & 0,287 \\
\hline RTS & 0,195 & 1,638 & 0,159 & 1,651 & 0,218 & 1,383 & 0,276 & 1,232 \\
\hline CNX & 0,662 & 0,411 & 0,777 & 0,443 & 0,498 & 0,893 & 0,642 & 0,755 \\
\hline $\mathrm{SCl}$ & 0,877 & 0,131 & 0,096 & 1,975 & 0,224 & 1,367 & 0,324 & 1,154 \\
\hline IPC & 0,984 & 0,016 & 0,826 & 0,376 & 0,881 & 0,397 & 0,726 & 0,661 \\
\hline \multicolumn{9}{|l|}{ NIK não é causado por: } \\
\hline SP & 0,000 & 120,354 & 0,000 & 60,864 & 0,000 & 40,865 & 0,000 & 30,672 \\
\hline FTSE & 0,000 & 69,064 & 0,000 & 34,671 & 0,000 & 23,243 & 0,000 & 17,425 \\
\hline IBV & 0,000 & 43,870 & 0,000 & 22,637 & 0,000 & 15,598 & 0,000 & 11,832 \\
\hline RTS & 0,020 & 3,924 & 0,060 & 2,267 & 0,109 & 1,736 & 0,161 & 1,474 \\
\hline CNX & 0,527 & 0,639 & 0,541 & 0,775 & 0,343 & 1,129 & 0,356 & 1,105 \\
\hline $\mathrm{SCl}$ & 0,553 & 0,593 & 0,820 & 0,384 & 0,902 & 0,363 & 0,847 & 0,513 \\
\hline IPC & 0,000 & 55,241 & 0,000 & 28,244 & 0,000 & 18,997 & 0,000 & 15,160 \\
\hline \multicolumn{9}{|l|}{ FTSE não é causado por: } \\
\hline SP & 0,000 & 128,961 & 0,000 & 67,782 & 0,000 & 45,771 & 0,000 & 34,198 \\
\hline $\mathrm{NIK}$ & 0,000 & 7,891 & 0,002 & 4,191 & 0,006 & 3,054 & 0,016 & 2,363 \\
\hline IBV & 0,000 & 30,816 & 0,000 & 16,115 & 0,000 & 11,502 & 0,000 & 9,274 \\
\hline RTS & 0,441 & 0,818 & 0,241 & 1,371 & 0,245 & 1,320 & 0,282 & 1,220 \\
\hline CNX & 0,225 & 1,491 & 0,479 & 0,872 & 0,351 & 1,115 & 0,478 & 0,944 \\
\hline $\mathrm{SCl}$ & 0,653 & 0,426 & 0,376 & 1,057 & 0,402 & 1,032 & 0,457 & 0,970 \\
\hline IPC & 0,000 & 38,367 & 0,000 & 20,837 & 0,000 & 13,928 & 0,000 & 10,815 \\
\hline
\end{tabular}

Fonte: Resultados da pesquisa

da Índia e da China. Após a sexta defasagem, o retorno do mercado da Rússia passa a não ajudar mais a previsão do retorno desse mercado.

Para analisar o contexto da Bolsa do Japão, deve-se considerar o possível efeito de abertura dos mercados. O mercado, em Tóquio, é o primeiro a ser aberto e a previsibilidade do seu retorno é melhorada tendo em vista os retornos dos outros mercados que são abertos posteriormente. Para o mercado londrino, verifica-se que a sua previsibilidade sofre interferências dos mercados norte-americano, japonês, brasileiro e mexicano. Os mercados da Rússia, Índia e China não influenciam, no sentido de Granger, o mercado londrino em todas as defasagens apresentadas, mesmo o período tendo sido marcado pela forte crise russa em 1998.

A Tabela $4 \bullet$ mostra os resultados da causalidade de Granger para os mercados emergentes. É interessante verificar o retorno da Bolsa brasileira, o IBV. Conforme os resultados apresentados, a previsibilidade do retorno brasileiro não sofreu interferências de outros mercados com dois lags 
Tabela 4 Teste de causalidade de Granger: mercados emergentes (1995-2002)

\begin{tabular}{|c|c|c|c|c|c|c|c|c|}
\hline \multirow[b]{2}{*}{ Hipótese Nula (Ho) } & \multicolumn{2}{|c|}{$\operatorname{Lag}(2)$} & \multicolumn{2}{|c|}{$\operatorname{Lag}(4)$} & \multicolumn{2}{|c|}{$\operatorname{Lag}(6)$} & \multicolumn{2}{|c|}{$\operatorname{Lag}(8)$} \\
\hline & Prob. & F Statistic & Prob. & F Statistic & Prob. & F Statistic & Prob. & F Statistic \\
\hline \multicolumn{9}{|l|}{ IBV não é causado por: } \\
\hline SP & 0,294 & 1,226 & 0,016 & 3,043 & 0,005 & 3,078 & 0,006 & 2,719 \\
\hline NIK & 0,869 & 0,140 & 0,022 & 2,866 & 0,013 & 2,684 & 0,036 & 2,061 \\
\hline FTSE & 0,540 & 0,616 & 0,110 & 1,889 & 0,058 & 2,032 & 0,077 & 1,776 \\
\hline RTS & 0,205 & 1,584 & 0,025 & 2,801 & 0,020 & 2,505 & 0,044 & 1,995 \\
\hline CNX & 0,861 & 0,149 & 0,989 & 0,078 & 0,938 & 0,297 & 0,550 & 0,859 \\
\hline $\mathrm{SCl}$ & 0,970 & 0,030 & 0,242 & 1,370 & 0,181 & 1,479 & 0,122 & 1,593 \\
\hline IPC & 0,359 & 1,024 & 0,068 & 2,185 & 0,048 & 2,125 & 0,122 & 1,591 \\
\hline \multicolumn{9}{|l|}{ RTS não é causado por: } \\
\hline SP & 0,000 & 37,965 & 0,000 & 20,748 & 0,000 & 13,825 & 0,000 & 10,915 \\
\hline NIK & 0,014 & 4,257 & 0,013 & 3,175 & 0,039 & 2,219 & 0,048 & 1,956 \\
\hline FTSE & 0,207 & 1,575 & 0,006 & 3,590 & 0,026 & 2,395 & 0,030 & 2,138 \\
\hline IBV & 0,000 & 34,563 & 0,000 & 18,478 & 0,000 & 12,176 & 0,000 & 9,308 \\
\hline CNX & 0,727 & 0,318 & 0,277 & 1,277 & 0,481 & 0,917 & 0,693 & 0,698 \\
\hline $\mathrm{SCl}$ & 0,125 & 2,084 & 0,315 & 1,185 & 0,488 & 0,907 & 0,161 & 1,475 \\
\hline IPC & 0,000 & 26,993 & 0,000 & 15,882 & 0,000 & 11,330 & 0,000 & 8,534 \\
\hline \multicolumn{9}{|l|}{ CNX não é causado por: } \\
\hline SP & 0,000 & 21,523 & 0,000 & 13,991 & 0,000 & 9,240 & 0,000 & 7,494 \\
\hline NIK & 0,312 & 1,165 & 0,159 & 1,650 & 0,106 & 1,746 & 0,168 & 1,458 \\
\hline FTSE & 0,000 & 13,291 & 0,000 & 7,389 & 0,000 & 4,719 & 0,000 & 4,634 \\
\hline IBV & 0,000 & 22,263 & 0,000 & 13,661 & 0,000 & 9,277 & 0,000 & 7,500 \\
\hline RTS & 0,133 & 2,0196 & 0,148 & 1,696 & 0,220 & 1,376 & 0,397 & 1,048 \\
\hline $\mathrm{SCl}$ & 0,197 & 1,626 & 0,440 & 0,939 & 0,574 & 0,794 & 0,719 & 0,669 \\
\hline IPC & 0,000 & 27,834 & 0,000 & 16,761 & 0,000 & 11,261 & 0,000 & 8,605 \\
\hline \multicolumn{9}{|l|}{ SCI não é causado por: } \\
\hline SP & 0,428 & 0,849 & 0,519 & 0,809 & 0,228 & 1,358 & 0,436 & 0,997 \\
\hline NIK & 0,333 & 1,100 & 0,527 & 0,797 & 0,779 & 0,538 & 0,811 & 0,560 \\
\hline FTSE & 0,114 & 2,177 & 0,283 & 1,261 & 0,178 & 1,489 & 0,376 & 1,077 \\
\hline IBV & 0,282 & 1,267 & 0,609 & 0,675 & 0,436 & 0,981 & 0,585 & 0,819 \\
\hline RTS & 0,198 & 1,620 & 0,174 & 1,591 & 0,305 & 1,196 & 0,319 & 1,162 \\
\hline CNX & 0,146 & 1,925 & 0,252 & 1,342 & 0,411 & 1,018 & 0,605 & 0,797 \\
\hline IPC & 0,714 & 0,336 & 0,939 & 0,198 & 0,500 & 0,891 & 0,551 & 0,858 \\
\hline \multicolumn{9}{|l|}{ IPC não é causado por: } \\
\hline SP & 0,227 & 1,485 & 0,443 & 0,935 & 0,568 & 0,802 & 0,580 & 0,826 \\
\hline NIK & 0,986 & 0,014 & 0,529 & 0,794 & 0,403 & 1,031 & 0,433 & 1,000 \\
\hline FTSE & 0,403 & 0,909 & 0,188 & 1,540 & 0,107 & 1,743 & 0,043 & 1,998 \\
\hline IBV & 0,787 & 0,239 & 0,878 & 0,300 & 0,967 & 0,229 & 0,979 & 0,257 \\
\hline RTS & 0,084 & 2,477 & 0,008 & 3,474 & 0,022 & 2,471 & 0,033 & 2,096 \\
\hline CNX & 0,205 & 1,587 & 0,527 & 0,797 & 0,452 & 0,958 & 0,200 & 1,379 \\
\hline $\mathrm{SCl}$ & 0,937 & 0,065 & 0,239 & 1,378 & 0,407 & 1,024 & 0,321 & 1,158 \\
\hline
\end{tabular}

Fonte: Resultados da pesquisa

de defasagem. Somente após quatro lags, os retornos da Bolsa brasileira começam a sofrer a causalidade no sentido de Granger, dos outros mercados, ficando mais uma vez a Índia e a China de fora dessas interferências.

A previsibilidade do retorno do índice RTS parece também, genericamente, não sofrer influências apenas dos retornos das Bolsas da Índia e China. Segundo os resultados, a contribuição para a previsibilidade do retorno londrino acontece apenas para os retornos com quatro lags de defasagens.
O retorno do CNX Nifty, um dos principais índices do mercado indiano, não é influenciado pelos retornos dos mercados londrino, russo e chinês em todas as defasagens testadas. O mercado chinês é o mais peculiar de todos. A previsibilidade do seu retorno não sofre interferência de nenhum outro retorno dentre os países analisados para nenhuma defasagem apresentada.

Finalmente, é interessante observar que apenas o retorno do RTS foi significativo para ajudar a prever o retorno da Bolsa do México, representado pelo índice IPC, salvo a 
partir da oitava defasagem em que esse mercado também sofre interferência do mercado londrino.

Resumidamente, pode-se inferir que o retorno do mercado norte-americano e londrino são os mais influentes nos outros mercados, melhorando a previsibilidade em pelo menos cinco outros mercados, possuindo, assim, interferência em níveis globais. É interessante verificar que, dentre os mercados emergentes, os retornos de SP e FTSE não causam, no sentido de Granger, o mercado mexicano.

Verifica-se, nas Tabelas 3 e 4, que o retorno do índice Nikkei auxilia a previsão em apenas outros três mercados: FTSE, IBV e RTS, possuindo uma baixa relevância dentro do contexto financeiro global e nenhuma interferência nos mercados regionais asiáticos.

É importante verificar que apenas os retornos dos emergentes, Brasil e México, foram significativos para ajudar a previsão dos retornos dos mercados do Japão e do Reino Unido. Além disso, deve-se observar as causalidades bidirecionais que existem entre os retornos dos mercados norte-americano e londrino, japonês e londrino, brasileiro e japonês, brasileiro e londrino.

Ao mesmo tempo, percebe-se que o retorno no Brasil tem causalidade no sentido de Granger em quatro outros mercados sendo, assim, mais significativo que o retorno do mercado japonês, que auxilia a previsibilidade em apenas outros três mercados. Além disso, tem-se que os retornos na Índia e na China não possuem interferência na previsibilidade de nenhum outro mercado analisado. Essa última, principalmente, parece, ainda, estar fora do contexto financeiro internacional, uma vez que seus retornos, também, não são influenciados por nenhum outro mercado.

Os retornos dos países emergentes do Brasil, Rússia e Índia são fortemente previsíveis pelo desempenho dos retornos nos principais mercados capitalizados. Há, portanto, sobretudo em relação ao IBV e RTS, influências regionais e globais. O CNX só não é influenciado pelo retorno japonês

\section{Resposta do FTSE a uma inovação de uma unidade (\%)}

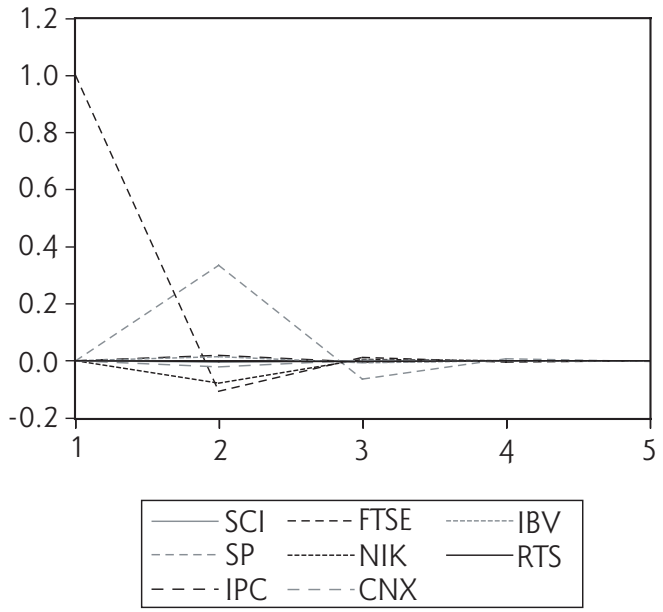

Fonte: Resultados da pesquisa sendo, desta maneira, influenciado pelas forças globais e não pelas regionais. Dentre os emergentes, o México parece não sofrer grandes influências. A previsibilidade do seu desempenho só seria influenciada pelo desempenho do retorno na Rússia, talvez pelo forte impacto e pelos possíveis efeitos cascatas que a crise nesse último possa ter gerado na Bolsa mexicana. Mais uma vez, observa-se relação bidirecional entre os retornos dos mercados brasileiro e russo, russo e mexicano.

A partir dos dados observados, pode-se inferir uma ordem crescente de endogeneidade entre as séries dos retornos, conforme colocado por Enders (1995), para estimação do modelo VAR e, conseqüentemente, para a análise das funções de reposta a impulsos. Utilizaram-se os resultados apresentados por seis defasagens. Dessa forma, tem-se a série $\mathrm{SCl}$ como a mais exógena, não sofrendo interferências de nenhum outro mercado. Essa conclusão pode ser explicada pelo baixo grau de abertura que o mercado financeiro da China apresenta, além da forte intervenção estatal na estrutura financeira desse país. Em seqüência, tem-se o retorno do SP e do IPC com uma interferência, os retornos dos índices FTSE, NIK e CNX com quatro interferências e o IBV e o RTS com cinco interferências.

Utilizando o procedimento de minimização dos critérios de informação de AIC e SBIC, estimaram-se diversas especificações (defasagens) para o modelo VAR de ordem $p$, sendo o de ordem igual a um, o que minimizou esses critérios. Assim, uma vez que os parâmetros da estimação, muitas vezes, não possuem interpretação direta, deve-se interpretar os gráficos da função de resposta a impulsos. Foram utilizados cinco períodos de observação para composição dos gráficos.

De acordo com os resultados da pesquisa, os retornos representados nos Gráficos $1 \mathbf{0}, 2 \mathbf{0}, 3 \bullet$ foram os mais sensíveis aos choques de uma unidade nos retornos dos outros mercados. No Gráfico 1 pode-se inferir que um cho-

\section{Resposta do NIK a uma inovação de uma unidade (\%)}

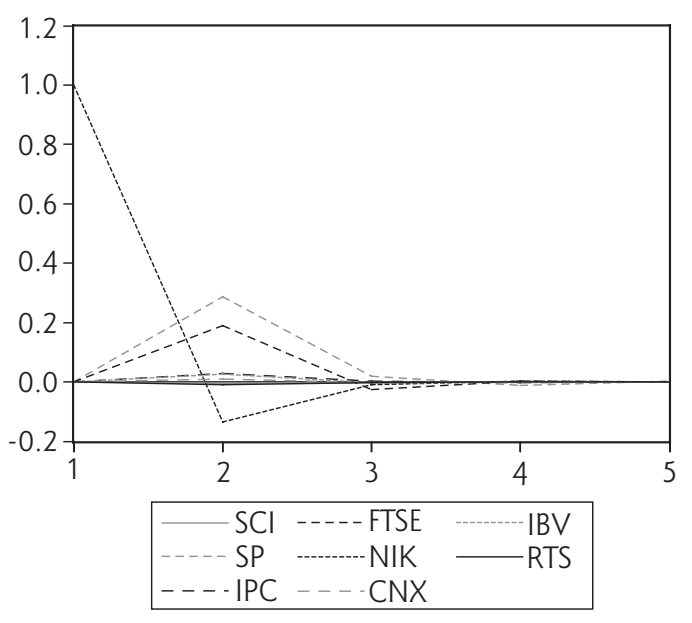

Fonte: Resultados da pesquisa 


\section{Resposta do RTS a uma inovação de uma unidade (\%)}

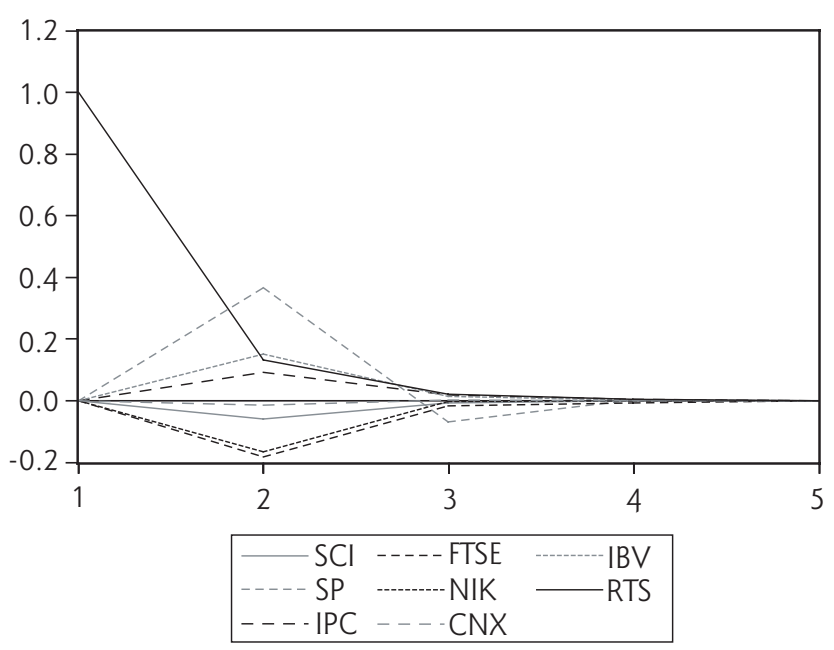

Fonte: Resultados da pesquisa

\section{Gráfico 3}

que em $1 \%$ no retorno do índice SP gera um efeito positivo, no segundo dia, de aproximadamente $0,3 \%$ no retorno do índice FTSE. Além disso, nesse mesmo gráfico, existe uma leve sensibilidade inversa do retorno desse índice em relação a um choque unitário do retorno do índice NIK, ou seja, um choque de uma unidade no NIK gera um retorno negativo de aproximadamente $0,1 \%$ no retorno do FTSE também com efeitos no segundo dia.

O retorno do índice NIK, representado no Gráfico 2, também, sofre influências apenas dos retornos das Bolsas mais desenvolvidas. Percebe-se que, no segundo dia, um choque de uma unidade nos retornos SP e FTSE geram, respectivamente, uma resposta positiva do retorno do índice em, aproximadamente, 0,3\% e 0,2\%.

Os gráficos das funções de resposta ao impulso para os demais mercados, ao contrário do que se poderia esperar, indicaram uma relativa estabilidade dos retornos dos mercados emergentes da China, do México, da Índia e do Brasil que parecem não ter sofrido fortes influências dos choques nos retornos de outros mercados. Assim sendo, optou-se por não apresentar tais gráficos. Além disso, verificou-se que choques em SP possuem impactos mais significativos na maioria dos mercados, mesmo que num curto período de tempo, mostrando a importância do mercado norteamericano dentro do contexto financeiro internacional.

Finalmente, no Gráfico 3 está representada a resposta do retorno do índice RTS em relação aos choques nos outros mercados. Pode-se inferir que esse mercado é muito influenciado por esses choques, sobretudo no segundo dia. A presença de um choque unitário nos retornos de SP, IBV e IPC geram, respectivamente, uma resposta positiva de, aproximadamente, $0,4 \%, 0,2 \%$ e $0,1 \%$. Além disso, conforme mostrado no mesmo gráfico, percebe-se que o retorno desse índice possui uma sensibilidade inversa com os retornos de FTSE e NIK. Um choque unitário nestes re- tornos gera uma resposta negativa de, aproximadamente, $0,2 \%$ no retorno do índice RTS.

Na Tabela $5 \bigcirc$ faz-se a mesma análise do teste de Granger para o período de 2003-2005 considerando os mercados capitalizados. Conforme observado, o mercado norteamericano sofreu relação de causalidade, para dois e quatro lags, dos retornos do mercado emergente brasileiro e não mais do retorno do mercado londrino.

A previsibilidade dos retornos do mercado japonês, além dos resultados apresentados no período anterior, passou a ser definida também pelo mercado indiano, possuindo o CNX causalidade no sentido de Granger para o retorno japonês em todos os lags apresentados. Dessa forma, parece que há um início do processo de regionalização do mercado asiático tendo em vista o alto crescimento econômico e do desenvolvimento do mercado de capitais nesses países, especialmente Índia e China.

Além disso, os retornos japoneses passaram, nesse período, a não exercer mais influência na previsibilidade do FTSE. O mesmo, no entanto, continuou fortemente influenciado pelos retornos dos mercados norte-americano, brasileiro e mexicano. Dessa forma, vê-se a forte presença desses emergentes dentro do cenário internacional.

Verificando a Tabela $6 \boldsymbol{\bullet}$, na qual foram colocados os resultados referentes aos mercados emergentes, pode-se inferir que o retorno no Brasil, mais uma vez em um resultado não muito esperado, não foi influenciado, no sentido de Granger, pelos retornos dos outros países, salvo duas defasagens quando foi influenciado pelo mercado indiano. Nesse período de estabilidade, em que a Rússia parece ter readquirido a confiança dos investidores internacionais, a previsibilidade do RTS passa a não sofrer causalidade dos principais mercados desenvolvidos do Japão e de Londres.

Dessa forma, vê-se que os mercados globais dos EUA, Brasil e México, ajudam a melhorar a previsibilidade do re- 
Tabela 5 | Teste de Causalidade de Granger: mercados capitalizados (2003-2005)

\begin{tabular}{|c|c|c|c|c|c|c|c|c|}
\hline \multirow[b]{2}{*}{ Hipótese Nula (Ho) } & \multicolumn{2}{|c|}{$\operatorname{Lag}(2)$} & \multicolumn{2}{|c|}{$\operatorname{Lag}(4)$} & \multicolumn{2}{|c|}{$\operatorname{Lag}(6)$} & \multicolumn{2}{|c|}{$\operatorname{Lag}(8)$} \\
\hline & Prob. & F Statistic & Prob. & F Statistic & Prob. & F Statistic & Prob. & F Statistic \\
\hline \multicolumn{9}{|l|}{ SP não é causado por: } \\
\hline NIK & 0,522 & 0,650 & 0,484 & 0,865 & 0,121 & 1,689 & 0,130 & 1,570 \\
\hline FTSE & 0,266 & 1,325 & 0,493 & 0,850 & 0,539 & 0,840 & 0,420 & 1,018 \\
\hline IBV & 0,018 & 4,054 & 0,049 & 2,397 & 0,168 & 1,522 & 0,292 & 1,207 \\
\hline RTS & 0,793 & 0,232 & 0,866 & 0,317 & 0,624 & 0,731 & 0,532 & 0,880 \\
\hline CNX & 0,131 & 2,037 & 0,169 & 1,615 & 0,287 & 1,232 & 0,572 & 0,834 \\
\hline $\mathrm{SCl}$ & 0,820 & 0,198 & 0,778 & 0,441 & 0,117 & 1,705 & 0,254 & 1,274 \\
\hline IPC & 0,229 & 1,476 & 0,517 & 0,812 & 0,591 & 0,775 & 0,360 & 1,101 \\
\hline \multicolumn{9}{|c|}{ NIKKEI não é causado por: } \\
\hline SP & 0,000 & 66,050 & 0,000 & 33,709 & 0,000 & 23,228 & 0,000 & 18,631 \\
\hline FTSE & 0,000 & 24,602 & 0,000 & 12,551 & 0,000 & 8,391 & 0,000 & 6,080 \\
\hline IBV & 0,000 & 18,599 & 0,000 & 10,080 & 0,000 & 7,120 & 0,000 & 5,425 \\
\hline RTS & 0,001 & 7,414 & 0,003 & 3,979 & 0,011 & 2,800 & 0,058 & 1,895 \\
\hline CNX & 0,006 & 5,192 & 0,004 & 3,853 & 0,012 & 2,752 & 0,015 & 2,389 \\
\hline $\mathrm{SCl}$ & 0,733 & 0,310 & 0,804 & 0,405 & 0,910 & 0,349 & 0,838 & 0,525 \\
\hline IPC & 0,000 & 25,6841 & 0,000 & 12,8379 & 0,000 & 8,568 & 0,000 & 6,708 \\
\hline \multicolumn{9}{|l|}{ FTSE não é causado por: } \\
\hline SP & 0,000 & 38,814 & 0,000 & 20,312 & 0,000 & 14,566 & 0,000 & 10,829 \\
\hline $\mathrm{NIK}$ & 0,635 & 0,454 & 0,442 & 0,936 & 0,268 & 1,271 & 0,222 & 1,335 \\
\hline IBV & 0,000 & 8,853 & 0,002 & 4,193 & 0,003 & 3,308 & 0,011 & 2,495 \\
\hline RTS & 0,163 & 1,818 & 0,525 & 0,805 & 0,415 & 1,013 & 0,282 & 1,224 \\
\hline CNX & 0,113 & 2,188 & 0,309 & 1,200 & 0,435 & 0,983 & 0,610 & 0,792 \\
\hline $\mathrm{SCl}$ & 0,887 & 0,120 & 0,678 & 0,578 & 0,167 & 1,524 & 0,288 & 1,214 \\
\hline IPC & 0,000 & 14,820 & 0,000 & 7,474 & 0,000 & 5,393 & 0,000 & 3,924 \\
\hline
\end{tabular}

Fonte: Resultados da pesquisa

Tabela 6 || Teste de causalidade de Granger: mercados emergentes (2003-2005)

\begin{tabular}{c|c|c|c|c|c|c|c|c}
\hline & \multicolumn{2}{|c|}{ Lag (2) } & \multicolumn{2}{c|}{ Lag (4) } & \multicolumn{2}{c|}{ Lag (6) } & \multicolumn{2}{c}{ Lag (8) } \\
\hline Hipótese Nula (Ho) & Prob. & F Statistic & Prob. & F Statistic & Prob. & F Statistic & Prob. & F Statistic \\
\hline IBV não é causado por: & & & & & & & & \\
SP & 0,255 & 1,370 & 0,160 & 1,651 & 0,289 & 1,229 & 0,487 & 0,935 \\
\hline NIK & 0,613 & 0,488 & 0,732 & 0,505 & 0,897 & 0,371 & 0,914 & 0,411 \\
\hline FTSE & 0,688 & 0,374 & 0,693 & 0,558 & 0,495 & 0,898 & 0,367 & 1,091 \\
\hline RTS & 0,799 & 0,224 & 0,892 & 0,278 & 0,590 & 0,775 & 0,620 & 0,780 \\
\hline CNX & 0,054 & 2,925 & 0,170 & 1,610 & 0,385 & 1,060 & 0,439 & 0,994 \\
\hline SCI & 0,659 & 0,417 & 0,272 & 1,290 & 0,445 & 0,969 & 0,377 & 1,076 \\
\hline IPC & 0,404 & 0,907 & 0,700 & 0,548 & 0,718 & 0,616 & 0,653 & 0,743 \\
\hline RTS não é causado por: & & & & & & & & \\
\hline SP & 0,001 & 6,848 & 0,008 & 3,466 & 0,016 & 2,636 & 0,008 & 2,624 \\
\hline NIK & 0,509 & 0,676 & 0,854 & 0,336 & 0,922 & 0,328 & 0,003 & 3,009 \\
\hline FTSE & 0,568 & 0,566 & 0,828 & 0,373 & 0,837 & 0,461 & 0,524 & 0,890 \\
\hline IBV & 0,000 & 11,061 & 0,000 & 5,767 & 0,001 & 3,952 & 0,000 & 3,613 \\
\hline CNX & 0,436 & 0,831 & 0,532 & 0,789 & 0,752 & 0,573 & 0,443 & 0,989 \\
\hline SCI & 0,644 & 0,440 & 0,180 & 1,571 & 0,368 & 1,087 & 0,431 & 1,005 \\
\hline IPC & 0,001 & 7,085 & 0,004 & 3,823 & 0,015 & 2,657 & 0,012 & 2,463 \\
\hline SP & & & & & & & &
\end{tabular}


(Continuação)

\begin{tabular}{c|c|c|c|c|c|c|c|c}
\hline & \multicolumn{2}{|c|}{ Lag (2) } & \multicolumn{2}{c|}{ Lag (4) } & \multicolumn{2}{c|}{ Lag (6) } & \multicolumn{2}{c}{ Lag (8) } \\
\hline Hipótese Nula (Ho) & Prob. & F Statistic & Prob. & F Statistic & Prob. & F Statistic & Prob. & F Statistic \\
\hline CNX não é causado por: & & & & & & & & \\
RTS & 0,340 & 1,079 & 0,357 & 1,096 & 0,126 & 1,667 & 0,203 & 1,378 \\
\hline SCI & 0,843 & 0,171 & 0,013 & 3,214 & 0,030 & 2,341 & 0,054 & 1,923 \\
\hline IPC & 0,004 & 5,514 & 0,001 & 4,840 & 0,000 & 4,204 & 0,000 & 4,086 \\
\hline SCI não é causado por: & & & & & & & & \\
\hline SP & 0,385 & 0,957 & 0,734 & 0,501 & 0,226 & 1,366 & 0,290 & 1,210 \\
\hline NIK & 0,172 & 1,765 & 0,448 & 0,926 & 0,057 & 2,054 & 0,113 & 1,629 \\
\hline FTSE & 0,982 & 0,018 & 0,947 & 0,183 & 0,375 & 1,076 & 0,445 & 0,987 \\
\hline IBV & 0,494 & 0,705 & 0,493 & 0,851 & 0,202 & 1,425 & 0,311 & 1,176 \\
\hline RTS & 0,164 & 1,811 & 0,412 & 0,991 & 0,471 & 0,932 & 0,653 & 0,743 \\
\hline CNX & 0,697 & 0,361 & 0,721 & 0,519 & 0,284 & 1,238 & 0,370 & 1,087 \\
\hline IPC & 0,902 & 0,102 & 0,988 & 0,080 & 0,406 & 1,021 & 0,410 & 1,032 \\
\hline SP & & & & & & & & \\
\hline IPIK não é causado por: & 0,123 & 2,099 & 0,225 & 1,422 & 0,258 & 1,292 & 0,019 & 2,319 \\
\hline FTSE & 0,252 & 1,381 & 0,542 & 0,774 & 0,397 & 1,041 & 0,210 & 1,362 \\
\hline IBV & 0,070 & 2,672 & 0,168 & 1,617 & 0,133 & 1,641 & 0,032 & 2,119 \\
\hline RTS & 0,014 & 4,290 & 0,067 & 2,207 & 0,129 & 1,655 & 0,011 & 2,504 \\
\hline CNX & 0,694 & 0,365 & 0,877 & 0,301 & 0,657 & 0,691 & 0,551 & 0,859 \\
\hline SCI & 0,263 & 1,339 & 0,492 & 0,853 & 0,460 & 0,947 & 0,557 & 0,851 \\
\hline & 0,402 & 0,913 & 0,408 & 0,998 & 0,643 & 0,707 & 0,516 & 0,899
\end{tabular}

Fonte: Resultados da pesquisa

torno desse índice. Dessa forma, observa-se a relevância que os mercados emergentes mais consolidados, como o brasileiro e o mexicano, possuem dentro do contexto financeiro internacional. A previsibilidade do CNX só não sofreu interferência do mercado londrino, sendo fortemente influenciada pelos EUA, Brasil e México.

Desse modo, pode-se inferir o início de inserção da Índia no contexto financeiro mundial. A China em nada alterou o seu perfil. Mais uma vez mostrou que a sua previsibilidade está livre de influências internacionais sendo elas dos mercados desenvolvidos ou em desenvolvimento, mostrando mais uma vez a dificuldade de penetração nesse mercado de capitais que é fortemente regulamentado pelo governo chinês e que ainda se encontra num estado incipiente embora haja um crescimento acelerado do número de companhias listadas. Entre 1995 e 2003, o número de companhias listadas passou de 188 para 780, representando um crescimento de 314\%. (WORLD FEDERATION OF EXCHANGES, 2005).

Por fim, a previsibilidade do retorno do índice mexicano mostrou-se influenciada pelo índice SP após oito lags de defasagem. Além disso, o seu retorno passou a não ser mais influenciado pelo retorno da Rússia. Para o período de estabilidade (2003-2005), os retornos dos mercados de Londres e do Brasil tiveram maior influência sobre o IPC.

Resumidamente, comparando-se os resultados para os anos de crises no mercado (1995-2002) com os resultados dos anos de estabilidade (2003-2005), pode-se inferir que a previsibilidade do retorno do índice NIK passou a ser a que mais sofre interferências dos retornos dos outros mercados, sendo, dessa maneira, auxiliado pelo comportamento dos mercados espalhados no mundo inteiro. O retorno do SP passa, nesse último período, a ser causado no sentido de Granger pelo retorno do Brasil assim como o FTSE. Além disso, esse último também sofreu interferências do retorno IPC.

É interessante observar que não existe uma única relação de causalidade bidirecional nesse período, mostrando que, em períodos de relativa estabilidade conjuntural as relações entre os retornos dos mercados financeiros, possivelmente, estão mais fundamentadas em aspectos macroeconômicos ou ajustes de posições nas carteiras dos investidores.

Verifica-se que o retorno no mercado brasileiro também é importante para a previsão dos retornos dos índices do resto do mundo, com exceção da China que mais uma vez mostrou-se imparcial em relação ao comportamento do retorno no restante dos mercados. O retorno no mercado mexicano causa, no sentido de Granger, os mercados do Japão e de Londres, tendo forte influência na previsibilidade dos retornos dos emergentes Rússia e Índia. Para esse período, os retornos do índice RTS perderam influência sobre os retornos dos mercados emergentes.

Além disso, observa-se a inserção do mercado indiano no contexto financeiro internacional. Se no período anterior o retorno da Índia não ajuda a melhorar as previsões dos outros mercados, nesse período de relativa estabilidade, o retorno do CNX passa a auxiliar a previsibilidade do mercado japonês e a sofrer interferências mais representativas dos seus companheiros emergentes (Brasil, China e 
México). Dessa forma, o seu comportamento é ditado pela referência global possuindo, no entanto, alguma relevância no contexto regional em que está inserido.

A estimação do modelo VAR para esse período respeitou a seguinte ordem crescente de endogeneidade: $\mathrm{SCl}$, IBV, SP, IPC, FTSE, RTS, CNX e NIK. De acordo com a minimização do critério de informação de Akaike, também foi estimado um modelo VAR (1) para esse período. Os gráficos de função de resposta a impulsos, cujos resultados foram mais significativos, estão plotados a seguir.

Nesse período, infere-se através do Gráfico 40 que o retorno do mercado brasileiro tornou-se mais sensível aos choques unitários nos outros mercados em relação ao período anterior. Tem-se que a variação em $1 \%$ dos retornos dos índices SP e CNX geram, respectivamente, uma variação de $0,2 \%$ e $0,1 \%$ dois dias depois. Além disso, o retorno brasileiro parece sofrer uma variação negativa de, aproximadamente, 0,2\% em choques nos retornos do FTSE e IPC, mostrando uma possível reversão de posição dos investidores. Mais uma vez, os retornos no mercado chinês mostraram-se independentes aos choques nos retornos dos demais mercados, mostrando que ele ainda se encontra relativamente fechado.

No Gráfico $5 \boldsymbol{\nabla}$, verifica-se que o retorno FTSE possui uma relação negativa com o seu próprio choque dois dias depois, respondendo positivamente (cerca de 0,35\%) a um

Resposta do IBV a uma inovação de uma unidade (\%)

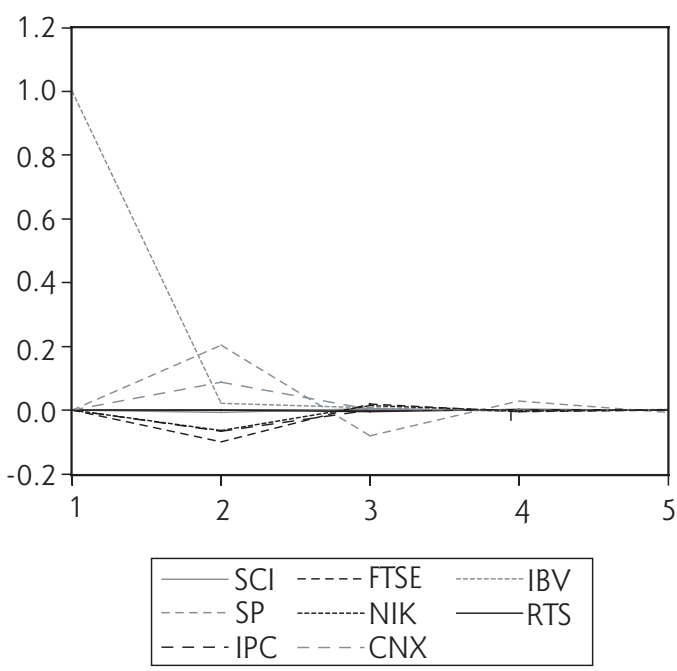

Fonte: Resultados da pesquisa

Gráfico 4 choque de $1 \%$ do retorno SP. Além disso, é interessante observar que a relação se inverte no $4^{\circ}$ dia, ou seja, o retorno responde positivamente $(0,05 \%)$ ao seu próprio choque e, negativamente $(0,1 \%)$, a choque do retorno SP. Percebe-se, através do formato do gráfico, as curvas de senóides amortecidas.

Nesse período de relativa estabilidade, o retorno RTS sofreu menos interferências, respondendo, positiva e significativamente, apenas aos choques dos retornos IBV e IPC. Há uma ligeira relação negativa com o retorno do índice FSTE, cujo choque, nesse último, é responsável por uma resposta em, aproximadamente, $0,1 \%$ do retorno do índice RTS.

Finalmente, nos Gráficos $6 \bullet$ e $7 \bullet$, foram encontrados os resultados das séries mais endógenas. No Gráfico 6, verifica-se que o retorno CNX responde positivamente em cerca de $0,2 \%$ ao choque de $1 \%$ no retorno SP e negativamente em cerca de $0,1 \%$ ao choque do retorno FTSE, igualmente, dois dias após o choque. No Gráfico 7, foram plotados os resultados encontrados para o retorno NIK, verificando-se a grande sensibilidade desse mercado ao choque no retorno SP. Obtém-se uma resposta de 0,4\% em NIK, dois dias após o choque de $1 \%$ do retorno norteamericano. Existe, além disso, uma pequena sensibilidade positiva, em cerca de $0,1 \%$, em relação ao retorno do índice FTSE.

\section{Resposta do FTSE a uma inovação de uma unidade (\%)}

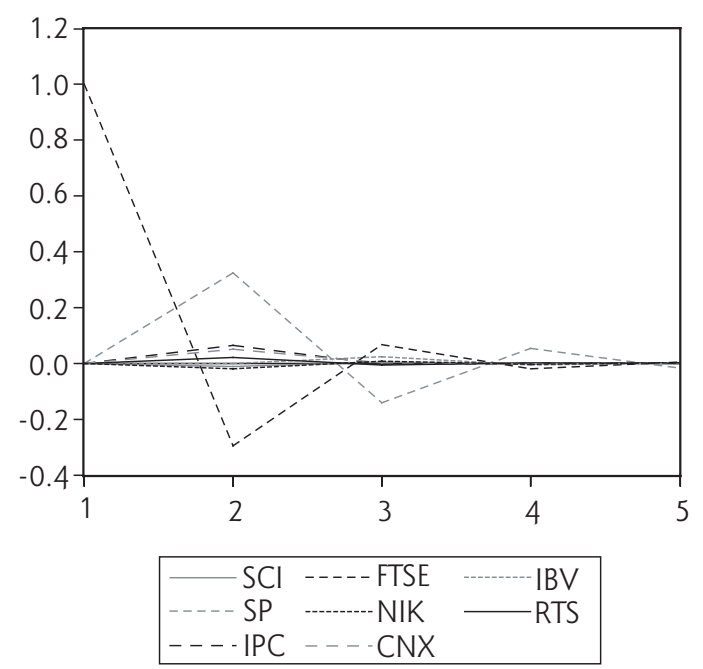

Fonte: Resultados da pesquisa

Gráfico 5 
Resposta do CNX a uma inovação de uma unidade (\%)

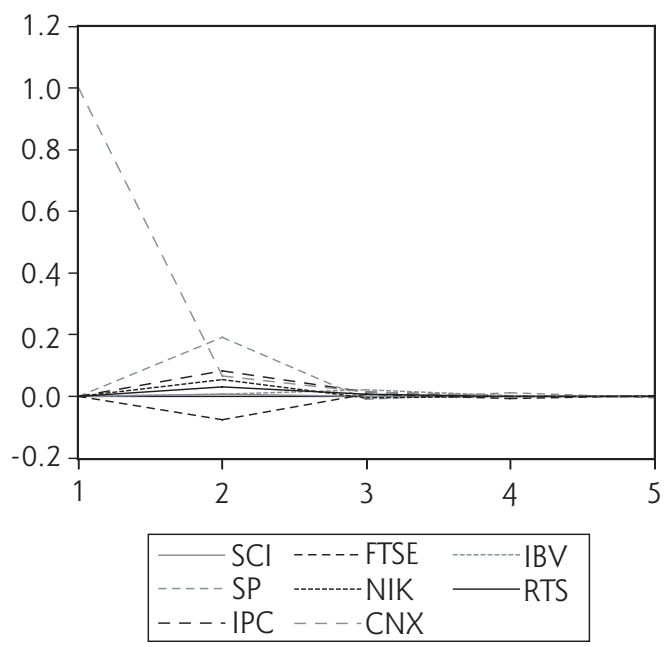

Fonte: Resultados da pesquisa

Gráfico 6

\section{Resposta do NIK a uma inovação de uma unidade (\%)}

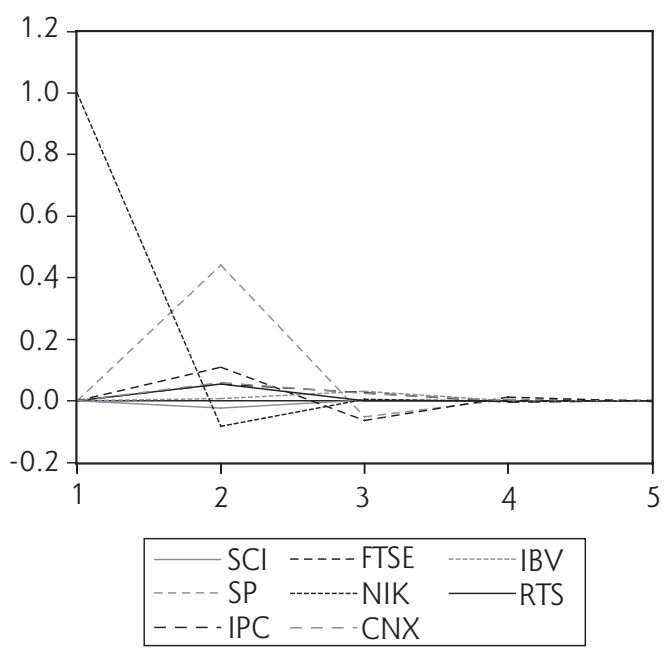

Fonte: Resultados da pesquisa

Gráfico 7

\section{CONCLUSÕES}

No intuito de estudar as relações de interdependência entre os principais mercados emergentes e capitalizados do mundo, esta pesquisa utilizou-se da metodologia de análise de séries temporais. Por meio de testes de causalidade de Granger, constatou-se que, de forma geral, considerando o período de 1995-2002, os retornos entre os mercados capitalizados se mostraram inter-relacionados. Além disso, constatou-se que os retornos dos países capitalizados ajudam na previsibilidade dos retornos dos países emergentes, salvo os retornos da Bolsa mexicana e da chinesa. Esse último, principalmente, parece ainda não estar inserido dentro do contexto financeiro internacional, uma vez que não causa e não sofre interferências, no sentido de Granger, dos demais mercados.

Observe-se, ainda, que o comportamento dos mercados emergentes está sendo influenciado, de uma forma mais significativa, pelo âmbito global (mercados norteamericano e londrino) e não pelo âmbito regional.

Para o período de 2003-2005, verificou-se que a relação de causalidade, no sentido de Granger, para os retornos dos mercados foi, relativamente, alterada. O retorno do índice CNX, por exemplo, mostrou-se mais influente no comportamento dos outros retornos. Vale ressaltar, novamente, que o retorno do índice NIKKEY, nesse período, se mostrou fortemente influenciado, no sentido de Granger, por todos os outros retornos, salvo o da Bolsa da China. Assim, constata-se que o mercado japonês não é um bom direcionador do mercado por ser o primeiro a ser aberto. Pelo contrário, o mercado japonês sofre interferências dos dias anteriores dos outros mercados.

A função de resposta a impulsos mostrou que outros mercados emergentes, como Brasil, Índia e México, responderam aos choques, mesmo que em curtos espaços de tempo, de outros mercados e essas respostas foram mais significativas aos choques dos mercados capitalizados.

Como sugestão para futuros trabalhos, seria interessante introduzir, no conjunto de variáveis analisadas nesta pesquisa, algumas variáveis macroeconômicas a fim de se captarem os possíveis efeitos que elas teriam no grupo. Uma análise descritiva mais profunda das especificidades de cada um desses mercados também auxiliaria a interpretação dos dados e compreensão da sua realidade. Além disso, é necessário que se aprofunde na discussão sobre as relações de equilíbrio de longo prazo entre os mercados, diante da riqueza da metodologia de cointegração. Dessa forma, novas informações poderiam ser direcionadas aos investidores, contribuindo para o desenvolvimento de novas estratégias de investimento. 


\section{Referências Bibliográficas}

AGGARWAL, R.; RIVOLI, P.. The relationship between the US and four Asian Stocks markets. ASEAN Economic Bulletin, v.6, n.1, p. 110-117, jul. 1989.

BIERENS, H.J.. Nonparametric cointegration analysis. Journal of Econometrics, 77, p. 379-404, 1997 apud KANAS, A.. Linkages between the US and european equity markets: further evidence from cointegration tests. Applied Financial Economics, v. 8, n. 6, p.607-614, dez. 1998.

BOLSA DE VALORES DE SÃO PAULO. Disponível em: <www.bovespa.com.br>. Acesso em: 22 set. 2005.

BROOKS, C.. Introductory econometrics for finance. Cambridge: Cambridge University Press, 2002.

CHEUNG, Y. L.; MAK, S. C.. The International transmission of stock markets fluctuation between developed markets and AsianPacific markets. Applied Financial Economics, v.2, n.1, p.43-47, mar. 1992.

ELTON, E. J. et al.. Moderna teoria de carteiras e análise de investimentos. São Paulo: Atlas, 2004.

ENDERS, W.. Applied econometrics time series. New York: John Wiley, 1995.

GERRITS, R.; YUCE, A.. Short and long term links among European and US stock Markets. Applied Financial Economics, v. 9, n.1, p.19, fev. 1999.

GILL, D.. Two decades of change in emerging markets. In: PARK, K.K.H., VAN AGTMAEL, A.W. (eds) The world's emerging stock markets: structure, development, regulation and opportunities. Chicago: Probus, 1993, p. 47-56, apud SANVICENTE, A.; LEITE, H.. Indice bovespa: um padrão para os investimentos brasileiros. São Paulo: Atlas, 1994.

GRIFFITHS, W. E.; HILL, C.; JUDGE, G. G.. Learning and practicing econometrics. New York: John Wiley \& Sons, 1993.

GUJARATI, D.. Econometria básica. São Paulo: Makron Booḱs, 2000.

HAMILTON, J.. Time series analysis. USA: Princeton University Press, 1994.

JOHANSEN, S.. Statistical analysis of cointegration vectors. Journal of Economic Dynamics and Control, 12, p. 231-254, 1988 apud KANAS, A. Linkages between the US and european equity markets: further evidence from cointegration tests. Applied Financial Economics, v. 8, n. 6, p.607-614, dezembro, 1998.

KANAS, A.. Linkages between the US and european equity markets: further evidence from cointegration tests. Applied Financial Economics, v. 8, n. 6, p.607-614, dez. 1998.

LAMOUNIER, W. M.. Comportamento dos preços no mercado spot de café no Brasil: análise dos domínios do tempo e da freqüência. São Paulo, Editora da Bolsa de Mercadorias e Futuros, 2003. (Prêmio BM\&F - Derivativos 2002).

; SILVA, J. T.. Análise das relações dos preços nos mercados de criarecria e engorda dos bovinos no estado de São Paulo. In: CONGRESSO BRASILEIRO DE ECONOMIA E SOCIOLOGIA RURAL, 36., 1998., Poços de Caldas. Agropecuária e agronegócio brasileiro: desafios e perspectivas. Brasília, SOBER, 1998. v.1, n.7, p.945-958.

MILLER, K.. Money Travels. NewsWeek, may 2, 2005. p.40.

MOBIUS, M.. O guia do investidor para mercados emergentes. São Paulo: Makron Books, 1996.

PAGAN, J. A.; SOYDEMIR, G.. On the linkages between equity markets in Latin America. Applied Economics Letters, v. 7, n. 3, p.207-210, mar. 2000.

RTS stock exchange. Disponível em: <www.rts.ru/?tid=425\&mtid=10000>. Acesso em: 13 set. 2005.

SANVICENTE, A.; LEITE, H.. Índice Bovespa: um padrão para os investimentos brasileiros. São Paulo: Atlas, 1994.

STOCK, J.; WATSON, M.. Econometria. São Paulo: Addison Wesley, 2004.

TABAK, B.; LIMA, E.. Causality and cointegration in stock markets: the case of Latin America. Revista Brasileira de Economia de Empresas, Brasília, v.3, n.2. Brasília, p. 27-45, 2003.

VAN AGTMAEL, A. W.. Two decades of change in emerging markets. In: PARK, K.K.H., VAN AGTMAEL, A.W. (eds) The world's emerging stock markets: structure, development, regulation and opportunities.Chicago: Probus, 1993, p. 17-45, apud SANVICENTE, A.; LEITE, H. Índice Bovespa: um padrão para os investimentos brasileiros. São Paulo: Atlas, 1994.

WORLD FEDERATION OF EXCHANGES. Disponível em: <www.world-exchanges.org.br> Acesso em: 22 set. 2005.

\section{NOTA - Endereço dos autores}

Universidade Federal de Minas Gerais

Programa de Mestrado em Ciências Contábeis

Rua Curitiba, $832-7^{\circ}$. andar - Sl. 703 - Centro

Belo Horizonte - MG

$30170-120$
Inst. Educ. da Bolsa de Mercadorias e Futuros

Rua Líbero Badaró, 471 - Centro

São Paulo - SP

01009-903 